\title{
Recessive anonychia totalis and dominant aplasia (or hypoplasia) of upper lateral incisors in the same kindred ${ }^{1}$
}

\author{
N. FREIRE-MAIA AND MARTA PINHEIRO \\ From the Department of Genetics, Federal University of Paraná, Curitiba, Brazil
}

SUMMARY This paper describes and discusses the occurrence of 2 genetic traits, autosomal recessive anonychia and autosomal dominant hypoplasia of the upper lateral incisors (ULI) in 4 (2 males and 2 females) members of 2 sibships of the same kindred. Three of them also had spaced teeth and agenesis of one or more third molars. Anonychia was also present in another dead sib. Many other cases of aplasia and/or hypoplasia of ULI, as well as persistence of deciduous ULI, have been verified in the same kindred.

Simple anonychia is a clinically and genetically heterogeneous group of conditions that may vary from absence of one or more fingernails and/or toenails to complete absence of all of them. In some cases, dystrophic nails may also occur in the same patients. Inheritance is either autosomal dominant or recessive. For reviews and case reports see Littman and Levin (1964), Timerman et al. (1969), Mahloudji and Amidi (1971), and McKusick (1975).

Upper lateral incisors (ULI) are among the most commonly absent or malformed teeth. Aplasia or hypoplasia of ULI is a trait usually accepted as being the result of an autosomal dominant gene with incomplete penetrance. Its variable expressivity may be seen not only among different members of the same kindred, but also in both sides of the same individual. Cases with possible autosomal recessive inheritance are also referred to in published reports. For original data and reviews see Sutter (1966), Alvesalo and Portin (1969), Woolf (1971), and McKusick (1975).

This paper presents what appears to be the first documented instance of simultaneous occurrence of autosomal recessive anonychia and autosomal dominant hypoplasia of ULI in the same patients.

\section{Case reports}

The pedigree (Fig. 1) comprises 6 generations and 144 Caucasians of Portuguese origin who live in the Central Brazilian state of Minas Gerais. Three sibs (V.18, V.25, V.26) from a consanguineous marriage

${ }^{1}$ This study was supported by grants from the National Council for Scientific and Technological Development (Brazil) and the World Health Organization.

Received for publication 26 April 1978 (first and second cousins, $F=5 / 64$ ), and a similarly inbred first cousin of theirs (V.64, $F=1 / 16$ ), had total absence of nails from birth as well as hypoplastic ULI, both deciduous and permanent. Anonychia of all fingers and toes was reported by the parents of V.58, a boy who died at the age of 22 days because of 'umbilical complications'. IV.24 and IV.28 had bilateral absence of ULI (both deciduous and permanent). Bilateral hypoplasia of deciduous and permanent ULI was a feature of 8 members of the kindred (IV.21, IV.25, IV.32, IV.34, IV. 37, V.4, V.15, and V.32), while in 3 (IV.27, V.34, and V.39) only the left ULI (both deciduous and permanent) was hypoplastic. Bilateral persistence of deciduous ULI occurred in 2 (V.17 and V.38). In the first, a 21-year-old male, they remained until the age of 13 ; in the second, a 13-year-old girl, they are still present. Absence of left and hypoplasia of right ULI (deciduous and permanent) were found in V.37. IV.31, who used a denture for a long time, could not remember which of the 2 ULI (deciduous and permanent) was hypoplastic. For the same reason, no information could be obtained from patients IV.23 and IV.30.

CASE V.18

She was thought to be the first family member to have shown complete absence of all finger and toenails from birth (Fig. 2). It did not affect her unless acid substances were in contact with the nail beds. Physical examination showed very tiny horny plates on the proximal region of the nail bed of both 5 th toes; these plates were easily peeled off by the patient without pain. $X$-rays of hands and feet showed no bone malformations. No dermatoglyphic 


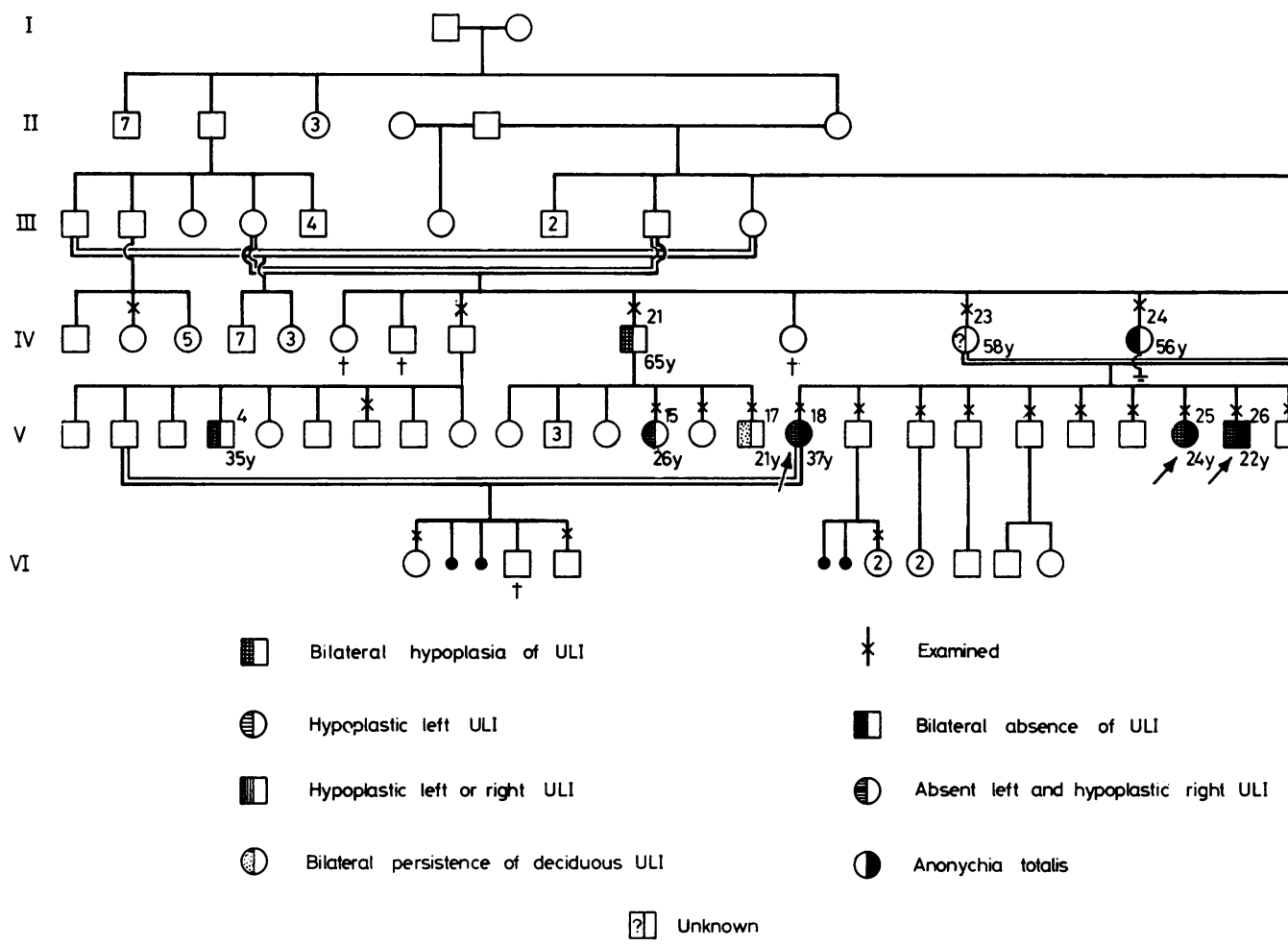

changes were found. Oral examination showed hypoplasia of the right ULI, both deciduous and permanent (the left one was also hypoplastic but had already been extracted), and agenesis of all 4 third molars. Agenesis of one or more third molars was described as a 'common' feature in the family.

CASE V. 25

She had the same abnormalities as those found in V.18 as well as widely spaced teeth (Fig. 3 ).

\section{CASE V. 26}

Apart from the presence of the left upper third molar and widely spaced teeth (Fig. 4), he was similar to cases V.18 and V.25.

CASE v. 64

He was practically identical to V.26, except for the presence of all 4 third molars.

\section{Discussion}

With regard to anonychia, our data show that (1) all affected individuals are inbred; (2) the segregation ratio $(5 / 18)$ is nearly $1 / 4 ;(3)$ there are 2 females and 3 males among the affected; and (4) the parents are all normal. This strongly suggests an autosomi recessive mode of inheritance.

The data for ULI are incomplete because $t \overrightarrow{\overrightarrow{B_{e}}}$ family members did not notice the trait and, therefore, were unable to give information about it their dead or absent relatives. The distribution of the trait among the living members suggests, howeve an autosomal dominant mode of inheritance with incomplete penetrance. From all the data, the smal! quantity examined showed that, of the 37 children of one known or presumed affected parent, there were 17 affected ( 8 males and 9 females) and 19 normal (14 males and 5 females). This last une?pected sex ratio $\left(\chi^{2}=4.26 ; P<0.05\right)$ is mostly due to one sibship with 9 males and 2 females. In the sibships with one known affected parent, there wex 9 normal (4 males and 5 females) and 7 affected $(3$ males and 4 females) children. The remaining dar are not suitable for genetic analysis.

All the 4 living patients with anonychia also hat hypoplastic ULI (both deciduous and permanent); 3 of them also had agenesis of one or more third molars and spaced teeth in different degrees. If they had been examined out of their family context, they could have been erroneously described as having am ectodermal dysplasia of the 2-3 subgroup, accordin to the clinical-mnemonic classification of Freire-Mara 


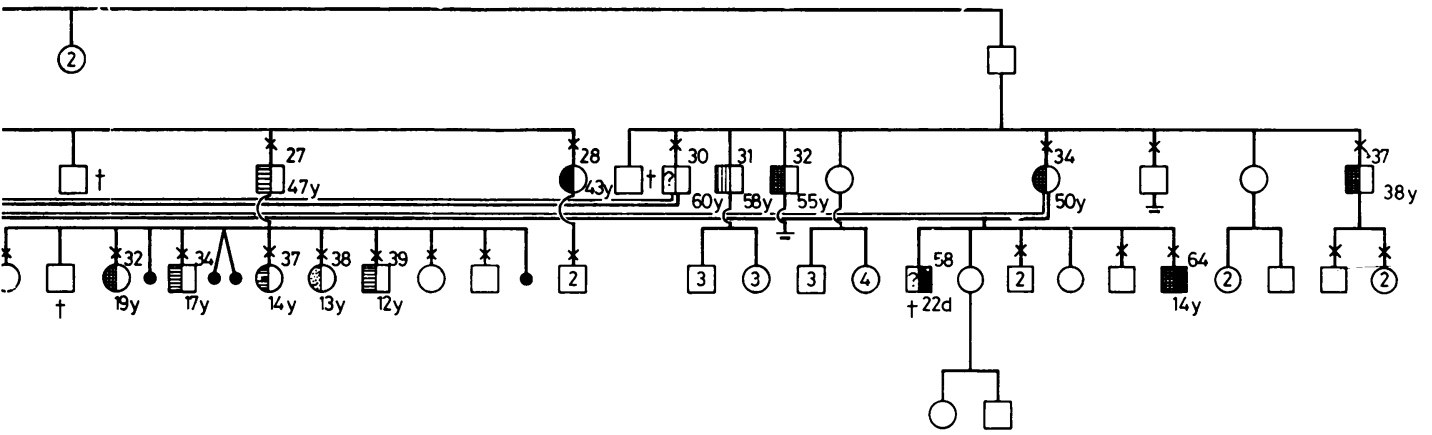

Fig. 1 Pedigree of the family. All members of generations I, II, and III are dead.
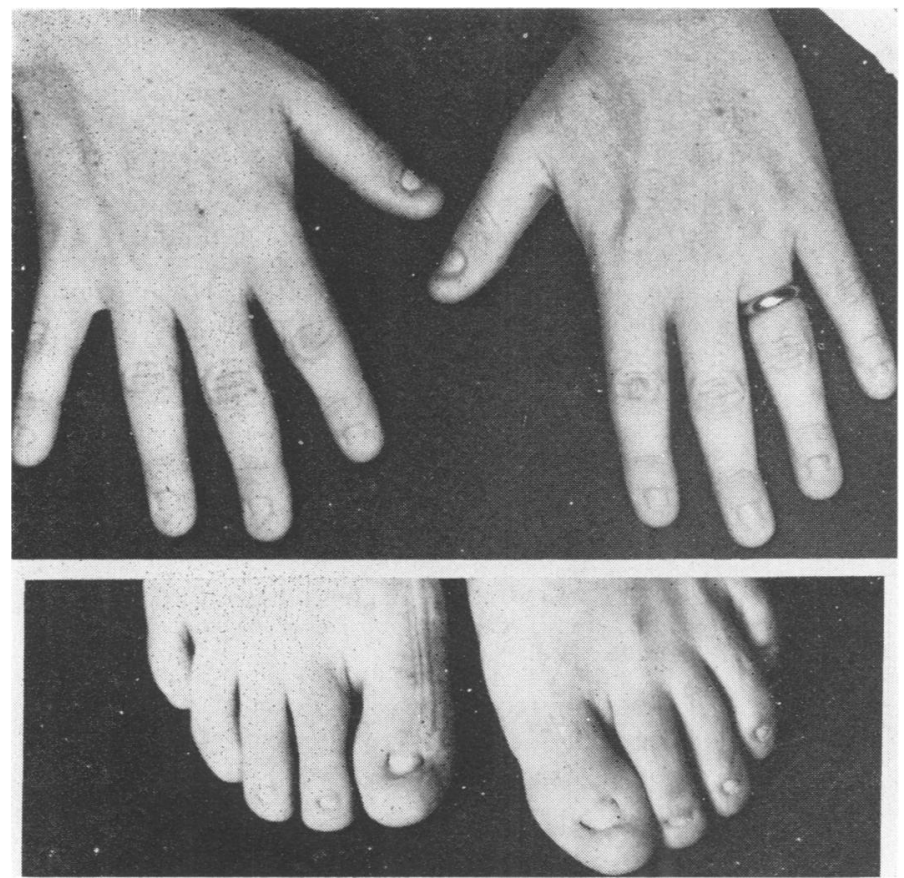

Fig. 2 Hands and feet of patient V. 18 showing complete absence of nails.

(1971, 1977). This leads us to a word of caution, and even to a serious warning regarding the description of 'new' genetic 'syndromes' characterised by only a few clinical signs and by data from small sibships; they may represent a mere chance combination of different abnormalities in the same individuals. Unfortunately, such occurrences have also been called 'syndromes' (Cohen, 1977), thus creating a new source of chaos in syndromology.

We could find no reason for the presence of spaced teeth in different degrees in three of our patients.

We are very grateful to Dr Ildeu Leite Naves for the $x$-rays of the hands and feet of our index cases. 


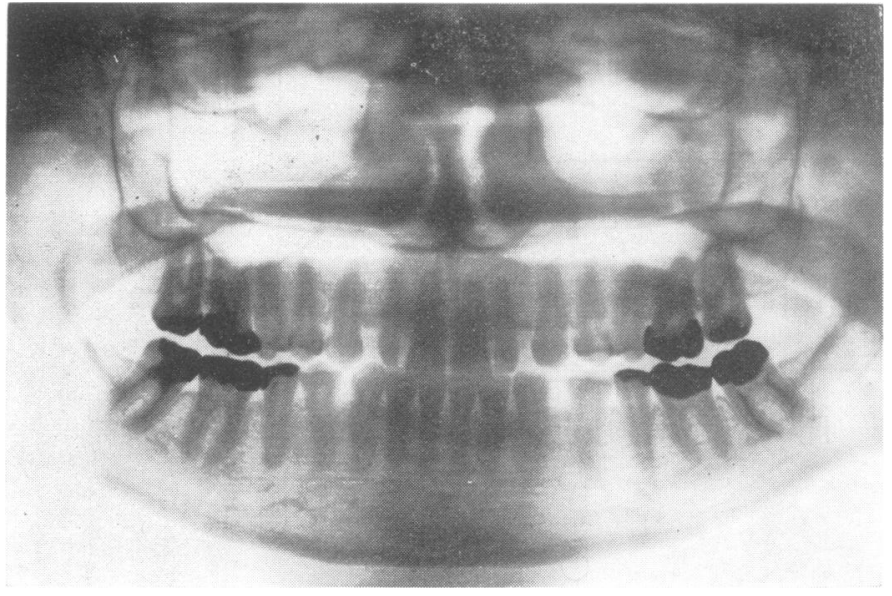

Fig. 3 Orthopantomogram of patient $V .2 .20$ when 25 years of age. Note the bilateral hypoplasia of ULI, the absence of all 4 thin $\vec{D}$ molars, and the spaced teeth.

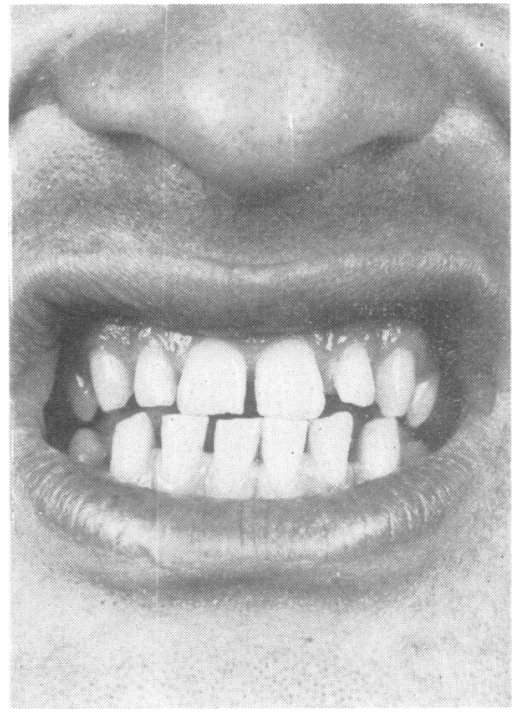

Fig. 4 Patient V.26 when 22 years of age showing bilateral hypoplasia of ULI and widely spaced teeth.

\section{References}

Alvesalo, L., and Portin, P. (1969). The inheritance patter $\frac{\mathbb{D}}{\mathbb{R}}$ of missing, peg-shaped and strongly mesio-distally reducef upper lateral incisors. Acta Odontologica Scandinavica, 2 公 563-575.

Cohen, M. M., Jr. (1977). On the nature of syndrome deline $\overrightarrow{0}$ tion. Acta Geneticae Medicae et Gemellologiae, 26, 103-110

Freire-Maia, N. (1971). Ectodermal dysplasias. Human Heredity, 21, 309-312.

Freire-Maia, N. (1977). Ectodermal dysplasias revisited. Ack Geneticae Medicae et Gemellologiae, 26, 121-131.

Littman, A., and Levin, S. (1964). Anonychia as a recessikg autosomal trait in man. Journal of Investigativo Dermatology. 42, 177-178.

McKusick, V. A. (1975). Mendelian Inheritance in Ma Johns Hopkins University Press, Baltimore.

Mahloudji, M., and Amidi, M. (1971). Simple anonychia. Journal of Medical Genetics, 8, 478-480.

Sutter, J. (1966). L'Atteinte des Incisives Latérales Supérieures? Presses Universitaires de France, Paris.

Timerman, I., Museteanu, C., and Simionescu, N. N. (1969 Dominant anonychia and onychodystrophy. Journal of Medical Genetics, 6, 105-106.

Woolf, C. M. (1971). Missing maxillary lateral incisors: genetic study. American Journal of Human Genetics, 28 289-296.

Requests for reprints to Professor N. Freire-Maia국 Department of Genetics, Federal University of Paraná, Caixa Postal AA, 80.000 Curitiba, Paran Brazil. 